\title{
Association of intensity of ventilation with 28-day mortality in COVID-19 patients with acute respiratory failure: insights from the PRoVENT-COVID study
}

Michiel T. U. Schuijt ${ }^{1 *}\left(\mathbb{D}\right.$, Marcus J. Schultz ${ }^{1,2,3}$, Frederique Paulus ${ }^{1,4}$ and Ary Serpa Neto ${ }^{1,5}$ for the PRoVENT-COVID Collaborative Group

\begin{abstract}
Background: The intensity of ventilation, reflected by driving pressure $(\triangle P)$ and mechanical power (MP), has an association with outcome in invasively ventilated patients with or without acute respiratory distress syndrome (ARDS). It is uncertain if a similar association exists in coronavirus disease 2019 (COVID-19) patients with acute respiratory failure.

Methods: We aimed to investigate the impact of intensity of ventilation on patient outcome. The PRoVENT-COVID study is a national multicenter observational study in COVID-19 patients receiving invasive ventilation. Ventilator parameters were collected a fixed time points on the first calendar day of invasive ventilation. Mean dynamic $\triangle P$ and MP were calculated for individual patients at time points without evidence of spontaneous breathing. A Cox proportional hazard model, and a double stratification analysis adjusted for confounders were used to estimate the independent associations of $\triangle \mathrm{P}$ and MP with outcome. The primary endpoint was 28-day mortality.
\end{abstract}

Results: In 825 patients included in this analysis, 28-day mortality was $27.5 \% . \triangle \mathrm{P}$ was not independently associated with mortality (HR 1.02 [95\% confidence interval 0.88-1.18]; $P=0.750$ ). MP, however, was independently associated with 28-day mortality (HR 1.17 [95\% Cl 1.01-1.36]; $P=0.031$ ), and increasing quartiles of MP, stratified on comparable levels of $\triangle P$, had higher risks of 28-day mortality (HR 1.15 [95\% Cl 1.01-1.30]; $P=0.028$ ).

Conclusions: In this cohort of critically ill invasively ventilated COVID-19 patients with acute respiratory failure, we show an independent association of MP, but not $\triangle \mathrm{P}$ with 28-day mortality. MP could serve as one prognostic biomarker in addition to $\triangle \mathrm{P}$ in these patients. Efforts aiming at limiting both $\triangle \mathrm{P}$ and MP could translate in a better outcome.

Trial registration Clinicaltrials.gov (study identifier NCT04346342).

Keywords: Coronavirus disease 2019, COVID-19, Acute respiratory failure, ICU, Invasive ventilation, Driving pressure, $\triangle \mathrm{P}$, Mechanical power of ventilation, Mechanical power, Mortality

*Correspondence: m.t.u.schuijt@amsterdamumc.n

${ }^{1}$ Department of Intensive Care, Amsterdam UMC, Location AMC, Meibergdreef 9,1105 AZ Amsterdam, The Netherlands

Full list of author information is available at the end of the article

(c) The Author(s) 2021, corrected publication 2021. Open Access This article is licensed under a Creative Commons Attribution 4.0 International License, which permits use, sharing, adaptation, distribution and reproduction in any medium or format, as long as you give appropriate credit to the original author(s) and the source, provide a link to the Creative Commons licence, and indicate if changes were made. The images or other third party material in this article are included in the article's Creative Commons licence, unless indicated otherwise in a credit line to the material. If material is not included in the article's Creative Commons licence and your intended use is not permitted by statutory regulation or exceeds the permitted use, you will need to obtain permission directly from the copyright holder. To view a copy of this licence, visit http://creativecommons.org/licenses/by/4.0/. The Creative Commons Public Domain Dedication waiver (http://creativecommons.org/publicdomain/zero/1.0/) applies to the data made available in this article, unless otherwise stated in a credit line to the data. 


\section{Introduction}

Mortality rates are high in coronavirus disease 2019 (COVID-19) patients who need invasive ventilation for acute respiratory failure $[1,2]$. Adequate prognostication is difficult though essential towards identifying patients with a high mortality risk, in order to consider alternative approaches hoping to improve outcomes. Studies have shown associations of several factors, like gender, age, comorbidities, biochemical markers and severity of illness scores with mortality [3-11]. Studies have also shown associations of various parameters of invasive ventilation, including degree of hypoxemia, positive endexpiratory pressure (PEEP), tidal volume $\left(\mathrm{V}_{\mathrm{T}}\right)$ and respiratory system compliance $(\mathrm{Crs})$ with outcome in these patients $[4,5,8-11]$.

In patients receiving ventilation because of a reason other than COVID-19, recent studies have shown associations of the driving pressure $(\Delta \mathrm{P})$ and the mechanical power of ventilation (MP) with mortality, both in patients with and patients without acute respiratory distress syndrome (ARDS) [12-20]. $\Delta \mathrm{P}$ is the pressure applied by the ventilator used to deliver of a $V_{T}$, as such representing the strain applied to the lung with each breath. MP is a summary value for the amount of energy per unit of time transferred from the ventilator to the respiratory system [15], and part of this energy acts directly on lung tissue, where it can cause harm. MP is calculated from $V_{T}$, $R R$ and the $\Delta \mathrm{P}$. These two parameters are attractive digital biomarkers, because they are easily calculable at the bedside, readily available and without costs.

Associations of $\triangle \mathrm{P}$ and MP with outcome in COVID19 patients that need invasive ventilation for acute respiratory failure have not yet been investigated. To investigate the impact of intensity of ventilation on 28-day mortality, we performed a preplanned analysis of a convenientlysized national multicenter cohort of COVID-19 patients receiving invasive ventilation because of acute respiratory failure. The hypothesis was that both $\Delta \mathrm{P}$ and $\mathrm{MP}$ have independent associations with mortality.

\section{Methods \\ Design}

This report concerns a preplanned secondary analysis of the PRoVENT-COVID study, an investigator-initiated, multicenter, retrospective observational study of invasively ventilated COVID-19 patients undertaken during the first 3 months of the pandemic at 22 ICUs in the Netherlands [8]. The study protocol of the PRoVENTCOVID study was prepublished [21], and a statistical analysis plan for the current analysis, written before assessing the database, is available online [22]. Details on the parent study have been published before [8]. The institutional review board of the Amsterdam UMC,
Amsterdam, The Netherlands, approved the study protocol, and need for patient informed consent was waived seen the observational design of the study.

\section{Patients}

Consecutive patients aged 18 years or older were eligible for participation in the PRoVENT-COVID study if admitted to one of the participating ICUs and had received invasive ventilation for acute respiratory failure due to COVID-19. The parent study had no exclusion criteria--for the current analysis we excluded patients with incomplete ventilation data to calculate $\Delta \mathrm{P}$ or MP. We also excluded patients that were lost to follow-up at day 28.

\section{Collected data, patient classification, and calculations}

Demographics and data regarding premorbid diseases and home medication were collected. On the first calendar day of invasive ventilation, in the first hour after intubation and thereafter every $8 \mathrm{~h}$ at fixed time points, ventilator settings and parameters were collected.

First, it was determined whether there was evidence of spontaneous breathing. Spontaneous breathing was deemed likely if: 1) patient was on a spontaneous ventilation mode, e.g., pressure support ventilation; or 2) patient was on a non-spontaneous ventilation mode with measured (total) $R R$ exceeding the set $R R>2$ breaths per minute. $\triangle \mathrm{P}$ and MP were only calculated for those time points at which there was no evidence of spontaneous breathing. Per each time point, dynamic $\Delta \mathrm{P}$ and $\mathrm{MP}$ were calculated using the following standard formulas:

$$
\begin{gathered}
\text { dynamic } \Delta P\left(\text { in cm } \mathrm{H}_{2} \mathrm{O}\right)= \\
\text { peak pressure }\left(P_{\text {peak }}\right) \\
\text {-PEEP } \quad[12,16] \\
\text { MP (in J/min })=0.098 * V_{T} * R R *\left(P_{\text {peak }}\right. \\
-0.5 * \Delta P) \quad[15,16,23,24]
\end{gathered}
$$

The $\Delta \mathrm{P}$ and MP were summarized as the mean of values over the first calendar day of ventilation.

\section{Outcomes}

The primary outcome was 28 -day mortality.

\section{Statistical analysis}

Continuous variables were reported as median (quartile 25\%-quartile 75\%) and compared with Wilcoxon ranksum tests, and categorical variables as number in percentage and compared with Fisher exact tests.

Variables with a $P<0.10$ in the univariable prediction model were selected and included in the multivariable model. Variables with $P<0.05$ in the multivariable 
model were selected as the covariates to be included in the final models. The following variables were considered for initial assessment: age, gender, body mass index, partial pressure of arterial oxygen/fraction of inspired oxygen $\left(\mathrm{PaO}_{2} / \mathrm{FiO}_{2}\right)$ ratio, plasma creatinine, medical history of hypertension, heart failure, diabetes, chronic kidney disease, chronic obstructive pulmonary disease, active hematological neoplasia and/or active solid tumor, use of angiotensin converting enzyme inhibitors, use of angiotensin II receptor blockers, use of a vasopressor or inotropes, fluid balance, $\mathrm{pH}$, mean arterial pressure, heart rate, and respiratory system compliance. These baseline covariates were selected according to clinical relevance and as used in previous study [8].

A multivariable (shared-frailty) Cox proportional hazard model including the covariates selected from those described above, and considering mean $\triangle \mathrm{P}$ or $\mathrm{MP}$ as the predictor of interest was constructed. To compare the relative predictive ability of both variables, an additional model was build including $\Delta \mathrm{P}$ and MP together, after assessing correlation and multicollinearity through Pearson's correlation coefficient and variance inflation factor, respectively. If multicollinearity was found, this model was discarded and we followed with the independent models for $\triangle \mathrm{P}$ and MP. For all models, the hazard ratio (HR) with its $95 \%$ confidence interval (CI) was reported. To further assess the impact of $\Delta \mathrm{P}$ and $\mathrm{MP}$, quintiles of increasing $\Delta \mathrm{P}$ and MP were created, and the estimates for each quintile derived from the model above were plotted. Also, a double stratification analysis was used to assess the impact of each of the variables when the other was kept constant. First, the cohort was stratified in six quantiles of $\Delta \mathrm{P}$ and then each quantile was further stratified in quartiles of increasing MP. The resulting quartiles have matched $\Delta \mathrm{P}$ and increasing MP. Then, the models above were reproduced to extract the hazard ratio for each of the quartiles. Similarly, the same strategy was followed to create quartiles with matched MP and increasing $\Delta \mathrm{P}$.

Kaplan-Meier curves were used to compare 28-day mortality among patients receiving high and low mean $\Delta \mathrm{P}$ and MP. The cutoff used for $\Delta \mathrm{P}$ was set at $15 \mathrm{~cm} \mathrm{H2O}$ $[12,16]$, though the ideal threshold for dynamic $\Delta \mathrm{P}$ is less certain than for static $\Delta \mathrm{P}$. The ideal cutoff for MP has not yet been established, but recent reports suggest that a value of $17 \mathrm{~J} / \mathrm{min}$ could be a reasonable cutoff for this parameter $[13,16,25]$.

Two sensitivity analyses were performed. First, the models were re-ran according to the degree of hypoxemia at the first day of invasive ventilation. For this, we used the cutoffs as used in the Berlin definition for ARDS: mild $(200<\mathrm{PaO} 2 / \mathrm{FiO} 2 \leq 300 \mathrm{mmHg})$, moderate $(100<\mathrm{PaO} 2 / \mathrm{FiO} 2 \leq 200 \mathrm{mmHg})$ and severe hypoxemia $(\mathrm{PaO} 2 / \mathrm{FiO} 2 \leq 100 \mathrm{mmHg})$. The models were repeated considering an interaction between the variable of interest $(\triangle \mathrm{P}$ or $\mathrm{MP})$ and the degree of hypoxemia at baseline. Second, the models were re-ran with an alternative validated equation for calculating MP in patients treated with pressure-controlled ventilation (PCV);

$$
\mathrm{MP}_{\mathrm{PCV}}(\text { in } \mathrm{J} / \mathrm{min})=0.098 * V_{T} * R R *(\Delta P+\mathrm{PEEP})
$$

All analyses were performed using $\mathrm{R}$ version 4.0.2 ( $\mathrm{R}$ Foundation for Statistical Computing), and a $P<0.05$ was considered significant.

\section{Results}

Patients

Of the originally enrolled 1102 patients in the PRoVENTCOVID study, 825 (74.9\%) were used in the current analysis (Additional file 1: Figure S1). Demographics characteristics and ventilation characteristics are presented in Table 1. Most patients had moderate ARDS, using severity classification of the current Berlin definition for ARDS. The most prevalent premorbid conditions were hypertension and diabetes mellitus. 227 (27.5\%) patients died within the first 28 days of follow-up. Other clinical outcomes are shown in Additional file 1: Table S1.

\section{$\Delta \mathrm{P}$ and $\mathrm{MP}$}

The median number of observations in the first calendar day of invasive ventilation at which ventilation data were collected was 3 [2 to 3]. In $88.2 \%$ [ 75 to $100 \%$ ] of observations per patient, there was no evidence of spontaneous breathing and $\triangle \mathrm{P}$ and MP could be calculated. Distribution of ventilator parameters are presented in Additional file 1: Figure $\mathrm{S} 2$.

In the first calendar day of invasive ventilation, median $\Delta \mathrm{P}$ was 14.0 [12.0 to 16.0$] \mathrm{cm} \mathrm{H}_{2} \mathrm{O}$ and median MP was 18.5 [15.5 to 22.2] J/min. $\Delta \mathrm{P}$ was $>15 \mathrm{~cm} \mathrm{H}_{2} \mathrm{O}$ in $270(32.7 \%)$ patients; MP was $>17 \mathrm{~J} / \mathrm{min}$ in $473(57.3 \%)$ patients.

The baseline risk model used for the adjusted analysis is shown in Additional file 1: Table S2. The following variables were independently associated with outcome and selected as confounders for the final models: age, chronic obstructive pulmonary disease, $\mathrm{pH}$ and heart rate. No indication of multicollinearity between $\Delta \mathrm{P}$ and $\mathrm{MP}$ was found in the model when including both variables together, thus, this model was not discarded (Additional file 1: Table S3).

\section{Association of $\triangle \mathrm{P}$ and MP with 28-day mortality}

$\Delta \mathrm{P}$ had no association with 28-day mortality, neither in the univariable (HR, 1.09 [95\% CI, 0.96 to 1.24]; $P=0.190)$, nor in the multivariable assessment (HR, 1.02 [95\% CI, 0.88 to 1.18]; $P=0.750$ ) (Fig. 1 and Table 2). 
Table 1 Baseline characteristics and clinical outcome of the included patients according to the cohort studied

\begin{tabular}{|c|c|}
\hline & Overall cohort $(n=825)$ \\
\hline Age, years & $65.0(57.0-71.0)$ \\
\hline Male gender - no (\%) & $600(72.7)$ \\
\hline Body mass index, $\mathrm{kg} / \mathrm{m}^{2}$ & $27.8(25.2-30.8)$ \\
\hline Transferred under invasive ventilation & $130(15.8)$ \\
\hline Days between intubation and admission & $0.0(0.0-0.0)$ \\
\hline Use of non-invasive ventilation prior to intubation - no (\%) & $67 / 751(8.9)$ \\
\hline Duration of non-invasive ventilation, $\mathrm{h}$ & $6.5(2.0-19.9)$ \\
\hline Chest CT scan performed - no (\%) & 268/799 (33.5) \\
\hline \multicolumn{2}{|l|}{ Lung parenchyma affected - no (\%) } \\
\hline $0 \%$ & $13 / 268(4.9)$ \\
\hline $25 \%$ & $88 / 268(32.8)$ \\
\hline $50 \%$ & $78 / 268(29.1)$ \\
\hline $75 \%$ & $71 / 268(26.5)$ \\
\hline $100 \%$ & $18 / 268(6.7)$ \\
\hline Chest X-ray performed - no (\%) & $454 / 525(86.5)$ \\
\hline \multicolumn{2}{|l|}{ Quadrants affected - no (\%) } \\
\hline 1 & $38 / 453(8.4)$ \\
\hline 2 & 108/453 (23.8) \\
\hline 3 & $129 / 453(28.5)$ \\
\hline 4 & 178/453 (39.3) \\
\hline \multicolumn{2}{|l|}{ Severity of ARDS - no (\%) } \\
\hline No & $9 / 813(1.1)$ \\
\hline Mild & 73/813 (9.0) \\
\hline Moderate & $488 / 813(60.0)$ \\
\hline Severe & 243/813 (29.9) \\
\hline \multicolumn{2}{|l|}{ Co-existing disorders - no (\%) } \\
\hline Hypertension & $279(33.8)$ \\
\hline Heart failure & $35(4.2)$ \\
\hline Diabetes & $191(23.2)$ \\
\hline Chronic kidney disease & $37(4.5)$ \\
\hline Baseline creatinine, $\mu \mathrm{mol} / \mathrm{L}^{*}$ & $78.0(62.0-98.0)$ \\
\hline Liver cirrhosis & $3(0.4)$ \\
\hline Chronic obstructive pulmonary disease & $68(8.2)$ \\
\hline Active hematological neoplasia & $12(1.5)$ \\
\hline Active solid neoplasia & $21(2.5)$ \\
\hline Neuromuscular disease & $3(0.4)$ \\
\hline Immunosuppression & $19(2.3)$ \\
\hline \multicolumn{2}{|l|}{ Previous medication - no (\%) } \\
\hline Systemic steroids & $31(3.8)$ \\
\hline Inhalation steroids & $92(11.2)$ \\
\hline Angiotensin converting enzyme inhibitor & $142(17.2)$ \\
\hline Angiotensin II receptor blocker & $90(10.9)$ \\
\hline Beta-blockers & $149(18.1)$ \\
\hline Insulin & $61(7.4)$ \\
\hline Metformin & $135(16.4)$ \\
\hline Statins & $251(30.4)$ \\
\hline Calcium channel blockers & $157(19.0)$ \\
\hline \multicolumn{2}{|l|}{ Vital signs at day 01} \\
\hline Heart rate, bpm** & $85.0(74.5-97.8)$ \\
\hline
\end{tabular}


Table 1 (continued)

Overall cohort $(n=825)$

Mean arterial pressure, $\mathrm{mmHg}^{* *}$

$80.5(73.8-88.0)$

Laboratory tests at day 01

$\mathrm{pH}^{* *}$

$7.36(7.31-7.41)$

Worst $\mathrm{PaO}_{2} / \mathrm{FiO}_{2}, \mathrm{mmHg}^{* * *}$

$123.9(94.3-160.1)$

$\mathrm{PaCO}_{2}, \mathrm{mmHg}^{* *}$

$44.5(39.5-50.3)$

Lactate $\mathrm{mmol} / \mathrm{L}^{* *}$

$1.1(0.9-1.4)$

Organ support at day $01-$ no (\%)

Continuous sedation

$790 / 823(96.0)$

Inotropic or vasopressor

640/823 (77.8)

Vasopressor

639/823 (77.6)

Inotropic

$41 / 823(5.0)$

Fluid balance, $\mathrm{mL}$

$539.0(0.0-1340.0)$

Urine output, $\mathrm{mL}$

$691.0(380.0-1155.0)$

Ventilation support at day 01

Assisted ventilation - no (\%)

$151 / 823(18.3)$

Tidal volume, $\mathrm{mL} / \mathrm{kg}$ PBW**a

$6.4(5.9-7.0)$

Tidal volume $\leq 8 \mathrm{~mL} / \mathrm{kg}$ PBW

$787(96.1)$

PEEP, $\mathrm{cmH}_{2} \mathrm{O}^{* *, a}$

Peak pressure, $\mathrm{CmH}_{2} \mathrm{O}^{* *, a}$

$13.0(11.0-14.7)$

Driving pressure, $\mathrm{cmH}_{2} \mathrm{O}^{* * a}$

$27.0(24.2-30.0)$

Driving pressure $>15 \mathrm{cmH}_{2} \mathrm{O}$

$14.0(12.0-16.0)$

$270(32.7)$

Mechanical power

Absolute, $\mathrm{J} / \mathrm{min}^{* *, a}$

$18.5(15.5-22.2)$

Mechanical power $>17 \mathrm{~J} / \mathrm{min}$

$473(57.3)$

Adjusted by compliance, $(\mathrm{J} / \mathrm{min}) /\left(\mathrm{mL} / \mathrm{cmH}_{2} \mathrm{O}\right)$

$0.57(0.43-0.75)$

Mechanical power $>0.23(\mathrm{~J} / \mathrm{min}) /\left(\mathrm{mL} / \mathrm{cmH}_{2} \mathrm{O}\right)$

$510(61.8)$

Compliance, $\mathrm{mL} / \mathrm{cmH}_{2} \mathrm{O}^{* * a}$

$32.1(26.9-39.6)$

Total respiratory rate, $\mathrm{mpm}^{* *, \mathrm{a}}$

$21.7(19.8-24.0)$

Set respiratory rate, $\mathrm{mpm}^{* *, a}$

$22.0(20.0-24.0)$

Minute ventilation, $\mathrm{L} / \mathrm{min}^{* *, a}$

$9.5(8.4-11.0)$

$\mathrm{FiO}_{2}{ }^{* *}$

$0.57(0.48-0.68)$

etCO $\mathrm{mmHg}^{* *}$

$36.9(33.0-42.0)$

Rescue therapy at day $01-$ no (\%)

Prone positioning

263/811 (32.4)

Duration, h

$8.0(4.0-13.0)$

Recruitment maneuver

$14 / 667(2.1)$

ECMO

$4 / 810(0.5)$

Use of NMBA

$212 / 822(25.8)$

Hours of use

$0.0(0.0-8.0)$

Clinical outcome

28-day mortality

$227(27.5)$

Data are median (quartile $25 \%$-quartile $75 \%$ ) or No (\%). Percentages may not total 100 because of rounding

CT computed tomography; ARDS acute respiratory distress syndrome; $\mathrm{PaO} 2$ arterial partial pressure of oxygen; FiO2 Fraction of inspired oxygen; $\mathrm{PaCO} 2$ arterial partial pressure of carbon dioxide; PEEP positive end expiratory pressure; etCO2 End tidal carbon dioxide; ECMO extracorporeal membrane oxygenation; NMBA neuromuscular blocking agent

*Most recent measurement in $24 \mathrm{~h}$ before intubation, or at ICU admission under invasive ventilation

**Aggregate as the mean of a maximum of four values

***Worst value of four available

a Only assessed in moments without spontaneous breathing activity 

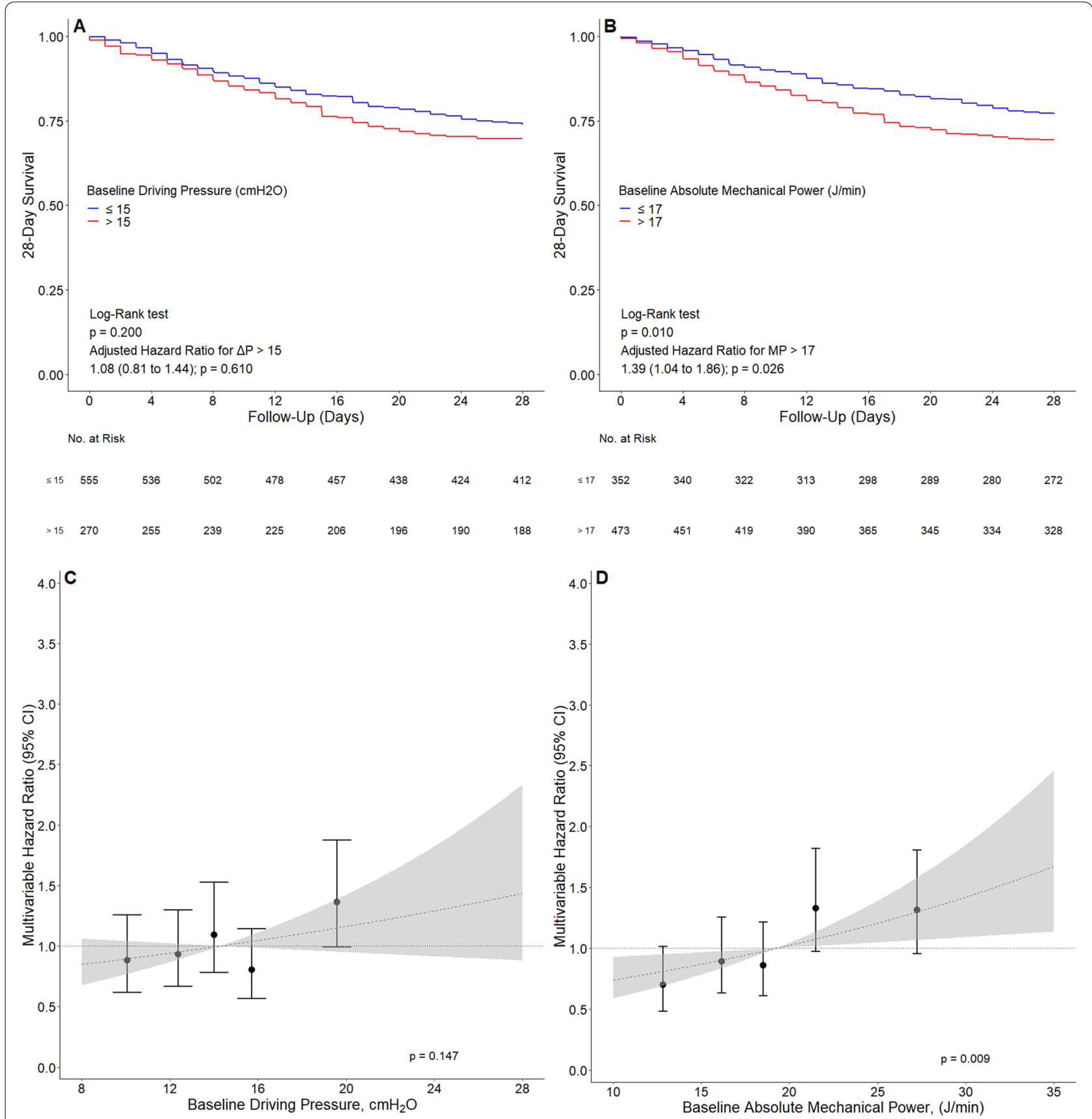

Fig. 1 Association between driving pressure and mechanical power and 28-day mortality. A Kaplan-Meier curve comparing the 28-day mortality of patients ventilated with $\triangle P>15 \mathrm{cmH}_{2} \mathrm{O}$ vs. $\triangle \mathrm{P} \leq 15 \mathrm{cmH}_{2} \mathrm{O}$. B Kaplan-Meier curve comparing the 28-day mortality of patients ventilated with $M P>17(\mathrm{~J} / \mathrm{min})$ versus $\leq 17(\mathrm{~J} / \mathrm{min}) . \mathbf{C}$ and $\mathbf{D}$ Effect of increasing levels of $\triangle \mathrm{P}$ or MP on 28-day mortality. Circles and error bars are hazard ratio and 95\% confidence interval for 5 quantiles of increasing $\triangle P$ or MP. Dashed lines and grey areas represent hazard ratio and $95 \%$ confidence interval for increasing values of $\triangle \mathrm{P}$ or MP analyzed as a continuous variable and centralized in the mean of each variable. All models were adjusted for age, chronic obstructive pulmonary disease, $\mathrm{pH}$, and heart rate. $\triangle \mathrm{P}$ : driving pressure; MP: mechanical power

Contrary, MP had an association with 28-day mortality, both in an univariable (HR, 1.17 [95\% CI, 1.02 to 1.33 ]; $P=0.020)$ and in a multivariable assessment (HR, 1.17 [95\% CI, 1.01 to 1.36 ]; $P=0.031$ ). While 28-day mortality was not different between patients with $\Delta \mathrm{P}>15 \mathrm{~cm} \mathrm{H}_{2} \mathrm{O}$ versus $\leq 15 \mathrm{~cm} \mathrm{H}_{2} \mathrm{O}$, 28-day mortality was higher in patients with $\mathrm{MP}>17 \mathrm{~J} / \mathrm{min}$ versus $\leq 17 \mathrm{~J} / \mathrm{min}$ (Fig. 1 ). 
Table 2 Univariable and multivariable model assessing the association of baseline driving pressure and mechanical power with 28-day mortality

\begin{tabular}{|c|c|c|c|c|c|c|c|c|}
\hline & \multicolumn{2}{|l|}{ Univariable model } & \multicolumn{2}{|c|}{ Multivariable model for $\Delta \mathrm{P}$} & \multicolumn{2}{|c|}{ Multivariable model for MP } & \multicolumn{2}{|c|}{$\begin{array}{l}\text { Multivariable model for } \Delta \mathrm{P} \\
\text { and MP }\end{array}$} \\
\hline & $\begin{array}{l}\text { Hazard ratio }(95 \% \\
\mathrm{Cl})\end{array}$ & $p$ value & $\begin{array}{l}\text { Hazard ratio }(95 \% \\
\mathrm{Cl})\end{array}$ & $p$ value & $\begin{array}{l}\text { Hazard ratio }(95 \% \\
\mathrm{Cl})\end{array}$ & $p$ value & $\begin{array}{l}\text { Hazard ratio }(95 \% \\
\mathrm{Cl})\end{array}$ & $p$ value \\
\hline \multicolumn{9}{|l|}{$\begin{array}{l}\text { Demographic char- } \\
\text { acteristics }\end{array}$} \\
\hline Age & $1.87(1.58-2.21)$ & $<0.001$ & $1.89(1.58-2.25)$ & $<0.001$ & $1.91(1.60-2.28)$ & $<0.001$ & $1.91(1.61-2.28)$ & $<0.001$ \\
\hline \multicolumn{9}{|l|}{ Co-existing disorders } \\
\hline COPD & $1.81(1.22-2.68)$ & 0.003 & $1.70(1.14-2.53)$ & 0.009 & $1.78(1.20-2.66)$ & 0.004 & $1.79(1.20-2.68)$ & 0.004 \\
\hline \multicolumn{9}{|l|}{$\begin{array}{l}\text { Laboratory tests at } \\
\text { day } 01\end{array}$} \\
\hline $\mathrm{pH}$ & $0.68(0.60-0.76)$ & $<0.001$ & $0.75(0.65-0.87)$ & $<0.001$ & $0.77(0.66-0.89)$ & $<0.001$ & $0.77(0.66-0.89)$ & $<0.001$ \\
\hline \multicolumn{9}{|l|}{ Vital signs at day 01} \\
\hline Heart rate & $1.23(1.08-1.41)$ & 0.001 & $1.17(1.01-1.35)$ & 0.031 & $1.16(1.01-1.34)$ & 0.035 & $1.16(1.01-1.34)$ & 0.037 \\
\hline \multicolumn{9}{|l|}{$\begin{array}{l}\text { Ventilatory variables } \\
\text { at day } 01\end{array}$} \\
\hline Driving pressure & $1.09(0.96-1.24)$ & 0.190 & $1.10(0.97-1.24)$ & 0.147 & - & - & $1.02(0.88-1.18)$ & 0.750 \\
\hline $\begin{array}{l}\text { Absolute mechani- } \\
\text { cal power }\end{array}$ & $1.17(1.02-1.33)$ & 0.020 & - & - & $1.18(1.04-1.35)$ & 0.009 & $1.17(1.01-1.36)$ & 0.031 \\
\hline
\end{tabular}

Continuous variables were included and the hazard ratio represents the increase in one standard deviation of the variable

$\triangle P$ driving pressure; $M P$ mechanical power; $C l$ confidence interval; $C O P D$ chronic obstructive pulmonary disease

If $\Delta \mathrm{P}$ was kept constant and only MP increased (i.e., due to increases in other components than $\Delta \mathrm{P}$ ) a statistically significant effect on outcome was found--increasing quartiles of MP, stratified on comparable levels of $\Delta \mathrm{P}$, were associated with increased risk of 28-day mortality (HR, 1.15 [95\% CI, 1.01 to 1.30]; $P=0.028$ ) (Fig. 2). However, increasing quartiles of $\Delta \mathrm{P}$, stratified on comparable levels of MP, were not associated with 28-day mortality (HR, 1.02 [95\% CI, 0.90 to 1.15$] ; P=0.730$ ). No interaction between the effect of $\Delta \mathrm{P}$ or MP on 28-day mortality and the degree of hypoxemia at baseline was found (Table 3). The sensitivity analysis using an alternative equation for MP in patients under PCV did not change the findings (Additional file 1: Table S4, Figure S2 and S3).

\section{Discussion}

In this observational study assessing the association of $\triangle \mathrm{P}$ and MP on 28-day mortality of patients receiving invasive ventilation for acute respiratory failure related to COVID-19, higher $\Delta \mathrm{P}$ was not, but higher MP was associated with increased 28-day mortality after adjustment for confounders. In addition, when $\Delta \mathrm{P}$ was kept constant, progressive increments in MP, due to increase in other components, like $\mathrm{V}_{\mathrm{T}}$ or $\mathrm{RR}$, resulted in higher risks for 28-day mortality.

Comparing our patient cohort to COVID-19 patients in series of patients worldwide, baseline characteristics and 28-day mortality were similar [1, 11, 27-29]. Two large observational studies, originating from France and from the United States, reported a similar median $\Delta \mathrm{P}$, respectively 13 [10 to 17] and 15 [11 to 18 ] $\mathrm{cm} \mathrm{H}_{2} \mathrm{O}$. Thus far, MP has only been reported in one cohort of COVID19 patient [11], in which MP was much higher than in our cohort, 26.5 [18.6 to 34.9 ] versus 18.5 [15.5 to 22.2] $\mathrm{J} / \mathrm{min}$. It remains uncertain why we see this remarkable difference, as the same equation for MP was used. However, MP in our study was comparable to that reported in cohorts of patients with ARDS from another origin than COVID-19 [13, 16, 19].

This is the first study on associations of $\triangle \mathrm{P}$ and $\mathrm{MP}$ with mortality in invasively ventilated COVID-19 patients. In contrast to previous studies on $\Delta \mathrm{P}$ and MP in patients receiving ventilation because of a reason other than COVID-19, higher $\Delta \mathrm{P}$ was not associated with an increased risk of mortality. MP adjusted for confounders was associated with 28-day mortality, being in line with previous studies $[13,16,19]$. Furthermore, increasing quartiles of MP, stratified on comparable levels of $\Delta \mathrm{P}$, were associated with increased risk of 28-day mortality, showing the predictive value of MP in addition to $\Delta \mathrm{P}$, which is in line with a previous study in patients receiving ventilation because of a reason other than COVID-19 [18]. Recently, a study showed the adverse effect of the exposure to higher intensities of $\triangle \mathrm{P}$ and MP over time in critically ill patients receiving 

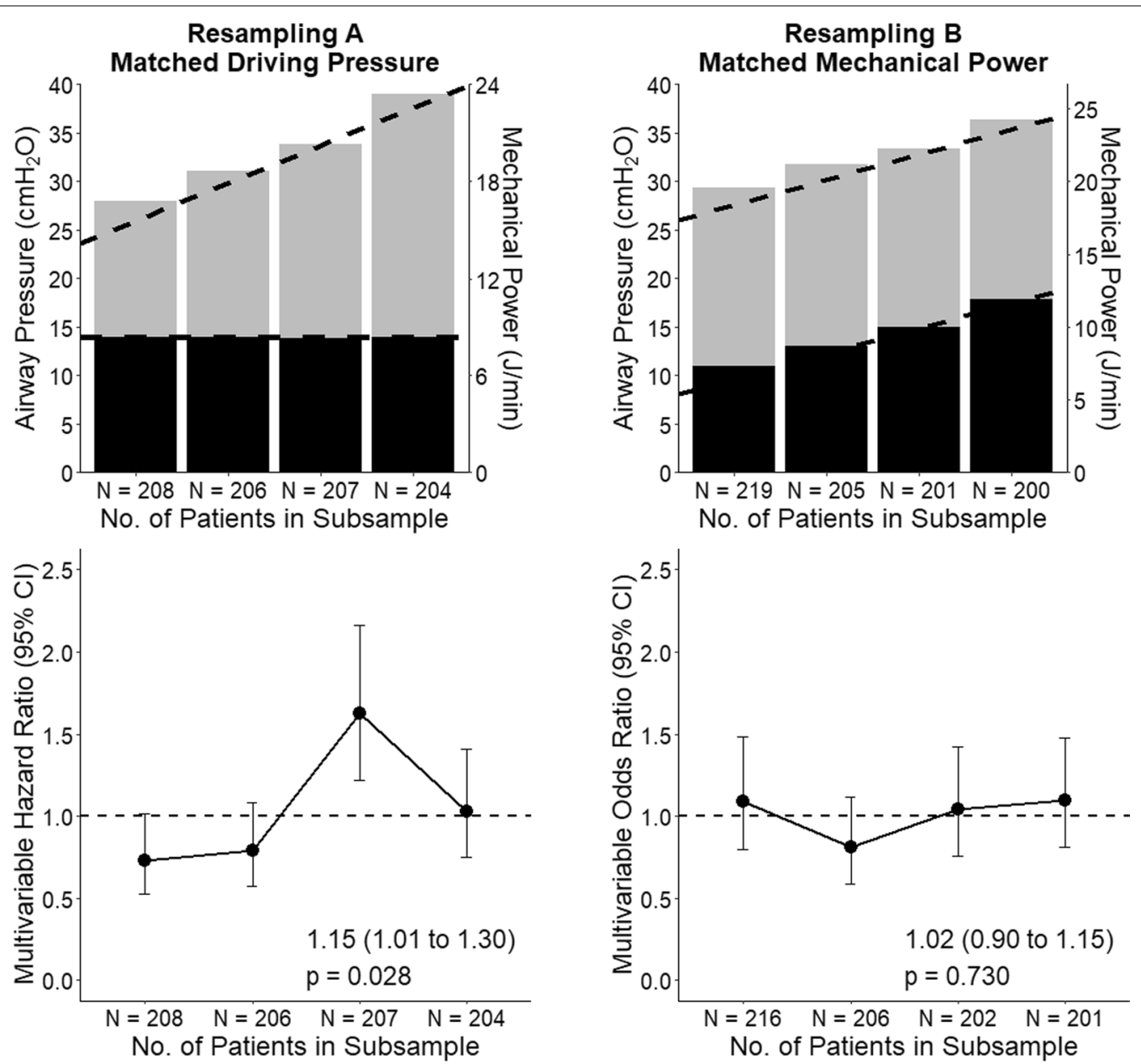

Mechanical Power

Driving Pressure

Fig. 2 Hazard ratio for 28-day mortality across relevant quartiles of driving pressure and mechanical power. A (left) Comparable values of $\triangle P$, but increasing values of MP across strata. Multivariable HR for increasing MP per stratum is presented below. B (right) Comparable values of MP, but increasing values of $\triangle \mathrm{P}$ across strata. Multivariable $\mathrm{HR}$ for increasing $\triangle \mathrm{P}$ per stratum is presented below. The $\mathrm{Y} 1$ axis is for airway pressure; the $\mathrm{Y} 2$ axis is for mechanical power. X axis reports cohort sample sizes. Circles and error bars in the lower panels are HR and $95 \%$ confidence interval for quartiles of increasing $\triangle \mathrm{P}$ and matched MP or vice-versa. All models were adjusted for age, chronic obstructive pulmonary disease, pH, and heart rate

Table 3 Effect of driving pressure and mechanical power on 28-day mortality according to severity of hypoxemia at baseline

\begin{tabular}{lll}
\hline & $\begin{array}{l}\text { Multivariable hazard ratio } \\
(\mathbf{9 5 \%} \mathbf{C l})\end{array}$ & P value \\
\hline $\begin{array}{lll}\text { Driving pressure } \\
\text { Mild ARDS }\end{array}$ & $1.66(0.97-2.84)$ & Reference \\
Moderate ARDS & $1.01(0.85-1.19)$ & 0.083 \\
Severe ARDS & $1.12(0.89-1.40)$ & 0.173 \\
Mechanical power & & \\
Mild ARDS & $1.10(0.59-2.05)$ & Reference \\
Moderate ARDS & $1.11(0.94-1.29)$ & 0.899 \\
Severe ARDS & $1.30(1.01-1.68)$ & 0.635 \\
\hline
\end{tabular}

$P$ value for the interaction between severity of ARDS and the variable of interest $\mathrm{Cl}$ confidence interval ventilation due to respiratory failure due to a reason other than COVID-19 [16].

In our analysis, the signal for mechanical power was stronger than for $\Delta \mathrm{P}$. Over recent years, $\Delta \mathrm{P}$ has become a value targeted by the clinician not to exceed a certain value. This may be caused by the fact that mechanical power is more difficult to calculate at the bedside than $\Delta \mathrm{P}$. Consequently, this may have resulted in lower $\Delta \mathrm{P}$ levels with a narrow distribution in the current cohort, and this may have led to insufficient statistical power to test whether $\Delta \mathrm{P}$ has a statistical association with outcome. In our cohort, MP was often high and with a broad distribution. 
Despite the finding that the association of $\Delta \mathrm{P}$ with 28-day mortality did not reach statistical significance, $\Delta \mathrm{P}$ remains an important digital biomarker. Limiting $\Delta \mathrm{P}$ has been found to have a strong potential to improve outcome in other patient cohorts $[13,14,16]$. Besides, $\Delta \mathrm{P}$ is much easier to calculate at the bedside compared to MP. In daily practice, MP may serve as an additional digital biomarker that is calculated by, and presented on the screen of the ventilator. Nevertheless, randomized controlled trials evidence remains needed to understand the true and independent value of limiting $\triangle \mathrm{P}$ and $\mathrm{MP}$.

Various equations for calculating MP have been studied and reported in recent years [16-20, 25, 30]. As transpulmonary pressures and plateau pressures were not routinely measured, we used dynamic driving pressure in the MP equation. Recent findings suggest that this substitution is reliable [30], and other validated this approach [16]. Aside, using the dynamic $\Delta \mathrm{P}$ simplifies the calculation of MP at the bedside. The sensitivity analysis, using another previously validated equation for MP in patients under PCV [26] did not change the findings.

Our study has several strengths. The study was conveniently-sized, and included a large number of centers. Also, both academic and non-academic centers participated, improving the generalizability of our findings. Granular ventilation data were collected by trained study personnel. We restricted the analysis to patients without the evidence of spontaneous breathing, as both $\Delta \mathrm{P}$ and MP cannot yet be calculated in a reliable way in patients with spontaneous breathing, and we adhered to a prepublished statistical analysis plan.

Our study also has limitations. In this study we did not collect blood biomarkers, like D-dimer levels, which have been shown to have a strong association with mortality [10]. Therefore, we could not add them to our models. Likewise, pulmonary embolism was not included in our models, which could be a confounding factor, as increased death space could result in a higher MP. Furthermore, the disease severity scores were not included, as the participating centers used different scores, which are not mutually exclusive. However, multiple baseline covariates were used in our models, representing multiple organ systems, supportive treatments and pre-existing comorbidities, being in line with previous studies investigating the impact of $\Delta \mathrm{P}$ and MP $[16,18,19]$. Also, during the first half of 2020 , there was no standard use of dexamethasone or tocilizumab, which may influence patient outcome. Another limitation is that normalization of MP by respiratory system compliance or predicted body weight has shown superior predictive value over non-normalized MP [17]. However, normalized MP has been less validated in comparison to absolute MP. Also, it is unknown whether this relationship simply reflects more an association between respiratory system compliance and patient outcome.

\section{Conclusion}

In this cohort of COVID-19 patients that received invasive ventilation for acute respiratory failure, both a higher MP and increasing quartiles of MP stratified on comparable levels of $\Delta \mathrm{P}$ were associated with increased risk of 28-day mortality. Taken together, both $\Delta \mathrm{P}$ and MP are useful digital biomarkers for prognostication in invasively ventilated COVID-19 patients. Targeting lower MP, in addition to lower $\Delta \mathrm{P}$, may translate in better outcomes.

\section{Abbreviations}

ARDS: Acute respiratory distress disease; $\mathrm{Cl}$ : Confidence interval; $\mathrm{C}_{\mathrm{RS}}$ : Respiratory system compliance; COVID-19: Coronavirus disease 2019; $\triangle \mathrm{P}$ : Driving pressure; ECMO: Extracorporeal membrane oxygenation; $\mathrm{FiO}_{2}$ : Fraction of inspired oxygen; HR: Hazard ratio; ICU: Intensive care unit; MP: Mechanical power of ventilation; NMBA: Neuromuscular blocking agents; $\mathrm{PaCO}_{2}$ : Partial pressure of arterial carbon dioxide; $\mathrm{PaO}_{2}$ : Partial pressure of arterial oxygen; $P_{\text {peak }}$ : Peak pressure; PEEP: Positive end-expiratory pressure; PRoVENT-COVID: PRactice of VENTilation in COVID-19; RR: Respiratory rate; $V_{T}$ : Tidal volume; VFD28: Ventilator-free days and alive at day 28.

\section{Supplementary Information}

The online version contains supplementary material available at https://doi. org/10.1186/s13054-021-03710-6.

Additional file 1. Table S1. Additional Clinical Outcomes in the Included Cohort. Table S2. Univariable and Multivariable Model of Covariates Selected for Inclusion in the Final Models. Table S3. Multivariable Model Assessing the Association of Driving Pressure and Mechanical Power with 28-Day Mortality in the Same Model. Table S4. Univariable and Multivariable Model Assessing the Association of Baseline Mechanical Power Calculated for Patients Under PCV* with 28-Day Mortality. Figure S1. Flowchart of Included Patients. Figure S2. Ranges of ventilator variables. Figure S3. Association Between Mechanical Power for PCV and 28-Day Mortality. Figure S4. Hazard Ratio for 28-Day Mortality Across Relevant Quartiles of Driving Pressure and Mechanical Power for PCV.

\section{Acknowledgements}

The authors would like to state a special gratitude towards all participating centers and all members of the PRoVENT-COVID Collaborative Group. The PRoVENT-COVID Collaborative Group investigators in alphabetic order: J.P. van Akkeren; A.G. Algera; C.K. Algoe; R.B. van Amstel; O.L. Baur; P. van de Berg; A.E. van den Berg; D.C.J.J. Bergmans; D.I. van den Bersselaar; F.A. Bertens; A.J.G.H. Bindels; M.M. de Boer; S. den Boer; L.S. Boers; M. Bogerd; L.D.J. Bos; M. Botta; J.S. Breel; H. de Bruin; S. de Bruin; C.L. Bruna; L.A. Buiteman-Kruizinga; O. Cremer; R.M. Determann; W. Dieperink; D.A. Dongelmans; H.S. Franke; M.S. GalekAldridge; M.J. de Graaff; L.A. Hagens; J.J. Haringman; N.F.L.Heijnen; S.Hiel; S.T. van der Heide; P.L.J. van der Heiden; L.L. Hoeijmakers; L. Hol; M. W. Hollmann; M.E. Hoogendoorn; J. Horn; R. van der Horst; E.L.K. le; D. Ivanov; N.P. Juffermans; E. Kho; E.S. de Klerk; A.W.M. Koopman; M. Koopmans; S. Kucukcelebi; M.A. Kuiper; D.W. de Lange; D. M. van Meenen; Ignacio Martin-Loeches; Guido Mazzinari; N. van Mourik; I. Martin-Loeches; S.G. Nijbroe; M. Onrust; E.A.N. Oostdijk; F. Paulus; C.J. Pennartz; J. Pillay; L. Pisani; I.M. Purmer; T.C.D. Rettig; J.P Roozeman; M.T.U. Schuijt; M.J. Schultz; A. Serpa Neto; M.E. Sleeswijk; M.R. Smit; P.E. Spronk; W. Stilma; A.C. Strang; A. M. Tsonas; P.R Tuinman; C.M.A. Valk; F.L.Veen; A.P.J. Vlaar; L.I. Veldhuis; P. van Velzen; W.H. van der Ven; P. van Vliet; P. 
van der Voort; H.H. van der Wier; L. van Welie; H.J.F.T. Wesselink; B. van Wijk; T. Winters; W.Y.Wong; A.R.H. van Zanten.

\section{Authors' contributions}

MTUS, MJS, FP, and ASN designed the study; all were involved in the analyses and drafting of the manuscript. All authors read and approved the final manuscript.

\section{Funding}

The Amsterdam University Medical Centers, location 'AMC' funded the study. It had no a role in the design, analysis, interpretation of data, writing or submission of this study.

\section{Availability of data and materials}

A dataset will be made available upon request to the corresponding authors one year after the publication of this study. The request must include a statistical analysis plan.

\section{Declarations}

\section{Ethics approval and consent to participate}

The institutional review boards of the participating centers approved the study protocol and need for patient informed consent was waived.

\section{Consent for publication}

Not applicable.

\section{Competing interests}

ASN reports personal fees from Dräger, outside of the submitted work. The other authors declare no competing interests.

\section{Author details}

'Department of Intensive Care, Amsterdam UMC, Location AMC, Meibergdreef 9, 1105 AZ Amsterdam, The Netherlands. ${ }^{2}$ Mahidol Oxford Tropical Medicine Research Unit (MORU), Mahidol University, Bangkok, Thailand. ${ }^{3}$ Nuffield Department of Medicine, University of Oxford, Oxford, UK. ${ }^{4}$ ACHIEVE, Centre of Applied Research, Faculty of Health, Amsterdam University of Applied Sciences, Amsterdam, The Netherlands. ${ }^{5}$ Department of Critical Care Medicine, Australian and New Zealand Intensive Care Research Centre (ANZIC-RC), Monash University, Melbourne, Australia.

Received: 8 June 2021 Accepted: 28 July 2021

Published online: 06 August 2021

\section{References}

1. Lim ZJ, Subramaniam A, Reddy MP, Blecher G, Kadam U, Afroz A, et al. Case fatality rates for covid-19 patients requiring invasive mechanical ventilation: a meta-analysis. Am J Respir Crit Care Med. 2021;203:54-66.

2. Domecq JP, Lal A, Sheldrick CR, Kumar VK, Boman K, Bolesta S, et al. Outcomes of patients with coronavirus disease 2019 receiving organ support therapies: the international viral infection and respiratory illness universal study registry. Crit Care Med. 2021;437-48.

3. Ferrando C, Malado-Artigas R, Gea A, Arruti E, Aldecoa C, Bordell A, et al. Patient characteristics, clinical course and factors associated to ICU mortality in critically ill patients infected with SARS-CoV-2 in Spain: A prospective, cohort, multicentre study. Rev Esp Anestesiol Reanim. 2020;67:425-37.

4. Ferrando C, Suarez-Sipmann F, Mellado-Artigas R, Hernández M, Gea A,

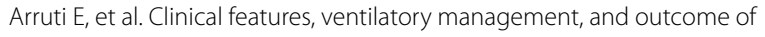
ARDS caused by COVID-19 are similar to other causes of ARDS. Intensive Care Med. 2020;46:2200-11.

5. Wendel Garcia PD, Fumeaux T, Guerci P, Heuberger DM, Montomoli J, Roche-Campo F, et al. Prognostic factors associated with mortality risk and disease progression in 639 critically ill patients with COVID-19 in Europe: initial report of the international RISC-19-ICU prospective observational cohort. EClinicalMedicine. 2020;25:1-11.

6. Li Q, Zhang T, Li F, Mao Z, Kang H, Tao L, et al. Acute kidney injury can predict in-hospital mortality in elderly patients with covid-19 in the ICU: a single-center study. Clin Interv Aging. 2020;15:2095-107.
7. Alharthy A, Aletreby W, Faqihi F, Balhamar A, Alaklobi F, Alanezi K, et al. Clinical characteristics and predictors of 28-day mortality in 352 critically ill patients with COVID-19: a retrospective study. J Epidemiol Glob Health. 2020;11:98.

8. Botta M, Tsonas AM, Pillay J, Boers LS, Algera AG, Bos LDJ, et al. Ventilation management and clinical outcomes in invasively ventilated patients with COVID-19 (PRoVENT-COVID): a national, multicentre, observational cohort study. Lancet Respir Med. 2021;9:139-48.

9. Grasselli G, Greco M, Zanella A, Albano G, Antonelli M, Bellani G, et al. Risk factors associated with mortality among patients with COVID-19 in intensive care units in Lombardy, Italy. JAMA Intern Med. 2020;180:1345-55.

10. Grasselli G, Tonetti T, Protti A, Langer T, Girardis M, Bellani G, et al. Pathophysiology of COVID-19-associated acute respiratory distress syndrome: a multicentre prospective observational study. Lancet Respir Med. 2020;8:1201-8.

11. COVID-ICU Group on behalf of the REVA Network and the COVID-ICU Investigators. Clinical characteristics and day- 90 outcomes of 4244 critically ill adults with COVID-19: a prospective cohort study. Intensive Care Med. 2021;47:60-73.

12. Amato MBP, Meade MO, Slutsky AS, Brochard L, Costa ELV, Schoenfeld DA, et al. Driving pressure and survival in the acute respiratory distress syndrome. N Engl J Med. 2015;372:747-55.

13. Serpa Neto A, Deliberato RO, Johnson AEW, Bos LD, Amorim P, Pereira $\mathrm{SM}$, et al. Mechanical power of ventilation is associated with mortality in critically ill patients: an analysis of patients in two observational cohorts. Intensive Care Med. 2018;44:1914-22.

14. Protti A, Andreis DT, Monti M, Santini A, Sparacino CC, Langer T, et al. Lung stress and strain during mechanical ventilation: Any difference between statics and dynamics? Crit Care Med. 2013;41:1046-55.

15. Gattinoni L, Tonetti T, Cressoni M, Cadringher P, Herrmann P, Moerer O, et al. Ventilator-related causes of lung injury: the mechanical power. Intensive Care Med. 2016;42:1567-75.

16. Urner M, Jüni $P$, Hansen $B$, Wettstein MS, Ferguson ND, Fan E. Timevarying intensity of mechanical ventilation and mortality in patients with acute respiratory failure: a registry-based, prospective cohort study. Lancet Respir Med. 2020;8:905-13.

17. Zhang Z, Zheng B, Liu N, Ge H, Hong Y. Mechanical power normalized to predicted body weight as a predictor of mortality in patients with acute respiratory distress syndrome. Intensive Care Med. 2019;45:856-64.

18. Tonna JE, Peltan I, Brown SM, Herrick JS, Keenan HT, Grissom CK, et al. Mechanical power and driving pressure as predictors of mortality among patients with ARDS. Intensive Care Med. 2020;46:1941-3.

19. Coppola S, Caccioppola A, Froio S, Formenti P, De Giorgis V, Galanti V, et al Effect of mechanical power on intensive care mortality in ARDS patients. Crit Care. 2020;24:1-10.

20. Parhar KKS, Zjadewicz K, Soo A, Sutton A, Zjadewicz M, Doig L, et al. Epidemiology, mechanical power, and 3-year outcomes in acute respiratory distress syndrome patients using standardized screening: an observational cohort study. Ann Am Thorac Soc. 2019;16:1263-72.

21. Boers NS, Botta M, Tsonas AM, Algera AG, Pillay J, Dongelmans DA, et al. PRactice of VENTilation in Patients with Novel Coronavirus Disease (PRoVENT-COVID): rationale and protocol for a national multicenter observational study in The Netherlands. Ann Transl Med. 2020;8:1251.

22. PROVENT-COVID [Internet]. [cited 2021 Mar 10]. https://sites.google.com/ view/provent-covid/.

23. Gattinoni L, Marini JJ, Collino F, Maiolo G, Rapetti F, Tonetti T, et al. The future of mechanical ventilation: Lessons from the present and the past. Crit Care. 2017;21:1-11.

24. Vasques F, Duscio E, Pasticci I, Romitti F, Vassalli F, Quintel M, et al. Is the mechanical power the final word on ventilator-induced lung injury? We are not sure. Ann Transl Med. 2018;6:395-395.

25. Giosa L, Busana M, Pasticci I, Bonifazi M, Macrì MM, Romitti F, et al. Mechanical power at a glance: a simple surrogate for volume-controlled ventilation. Intensive Care Med Exp. 2019;7:61.

26. Becher T, van der Staay M, Schädler D, Frerichs I, Weiler N. Calculation of mechanical power for pressure-controlled ventilation. Intensive Care Med. 2019:45:1321-3. https://doi.org/10.1007/s00134-019-05636-8.

27. Richardson S, Hirsch JS, Narasimhan M, Crawford JM, McGinn T, Davidson $\mathrm{KW}$, et al. Presenting characteristics, comorbidities, and outcomes among 5700 patients hospitalized with COVID-19 in the New York City Area. JAMA. 2020;323:2052-9.

28. Richards-Belle A, Orzechowska I, Gould DW, Thomas K, Doidge JC, Mouncey PR, et al. COVID-19 in critical care: epidemiology of the first 
epidemic wave across England, Wales and Northern Ireland. Intensive Care Med. 2020;46:2035-47.

29. Cummings MJ, Baldwin MR, Abrams D, Jacobson SD, Meyer BJ, Balough EM, et al. Epidemiology, clinical course, and outcomes of critically ill adults with COVID-19 in New York City: a prospective cohort study. Lancet. 2020;395:1763-70.
30. Chiumello D, Gotti M, Guanziroli M, Formenti P, Umbrello M, Pasticci I, et al. Bedside calculation of mechanical power during volume- and pressure-controlled mechanical ventilation. Crit Care. 2020;24:417-23.

\section{Publisher's Note}

Springer Nature remains neutral with regard to jurisdictional claims in published maps and institutional affiliations.
Ready to submit your research? Choose BMC and benefit from:

- fast, convenient online submission

- thorough peer review by experienced researchers in your field

- rapid publication on acceptance

- support for research data, including large and complex data types

- gold Open Access which fosters wider collaboration and increased citations

- maximum visibility for your research: over $100 \mathrm{M}$ website views per year

At BMC, research is always in progress.

Learn more biomedcentral.com/submissions 